\title{
Study of endometrial pathology in abnormal uterine bleeding
}

\section{Jignasha Parmar*, Deepak Desai}

Department of Obstetrics \& Gynaecology, SBKS Medical Institute and Research Centre, Pipariya, Ta-Waghodia, Vadodara- 391760, Gujarat, India

Received: 25 February 2013

Accepted: 22 March 2013

\author{
*Correspondence: \\ Dr. Jignasha Parmar, \\ E-mail: dr.jignashaparmar@gmail.com
}

(C) 2013 Parmar J et al. This is an open-access article distributed under the terms of the Creative Commons Attribution License, which permits unrestricted use, distribution, and reproduction in any medium, provided the original work is properly cited.

\begin{abstract}
Background: Abnormal uterine bleeding (AUB) is the commonest presenting symptom in gynaecology outpatient department. Endometrial sampling could be effectively used as a first diagnostic step in AUB, although at times, its interpretation could be quite challenging to the practicing obstetrician. This study was done to evaluate histopathology of endometrium for identifying endometrial causes of AUB. We observed the incidence of various pathology in different age groups presenting with abnormal uterine bleeding \& with respect to it were offered pharmacological management.

Methods: This was a study done at S B K S Medical Institute \& Research Centre, Vadodara, India on 155 patients who presented with AUB from February 2010-2012, these were the cases of isolated endometrial pathology diagnosed on histopathology were selected for analyses. A statistical analysis between age of presentation and specific endometrial causes was done using chi - square test.

Results: The most common age group presenting with AUB was 30- 40 yrs. The commonest pattern in these patients was normal cycling endometrium $(32.65 \%)$. The commonest pathology irrespective of the age group was disordered proliferative endometrium $(33.33 \%)$. Other causes identified were pregnancy associated conditions $(0.08 \%)$, benign endometrial polyp $(10.78 \%)$, endometrial hyperplasia without atypia $(0.05 \%)$, chronic endometritis $(0.03 \%)$, endometrial hyperplasia with atypia $(0.04 \%)$. Endometrial causes of AUB and age pattern was statistically significant with $p$ value $<0.05$.

Conclusions: There is an age specific association of endometrial lesions. In perimenopausal women AUB is most commonly dysfunctional in origin and in reproductive age group, one should rule out pregnancy associated conditions. The incidence of disordered proliferative pattern was significantly high in this study, suggesting an early presentation of these patients \& procuring success with pharmacological management.
\end{abstract}

Keywords: Abnormal uterine bleeding, Endometrium

\section{INTRODUCTION}

Abnormal uterine bleeding (AUB) is a common reason for women of all ages to consult their gynaecologist. It includes both organic and non - organic causes of uterine bleeding. Endometrial biopsy or curettage is a safe and effective diagnostic step in evaluation of abnormal uterine bleeding after ruling out medical causes. This study was done to evaluate the endometrial causes of AUB and to determine the specific pathology in different age groups and determining success with pharmacological management.

\section{METHODS}

This is a prospective study done on patients presenting with AUB from February 2010-2012 in the Department of Obstetrics \& Gynaecology in collaboration with the Department of Pathology of S B K S Medical Institute \& Research Centre, Vadodara (India). Patients were selected based on clinical details. The study material included a total no. of 155 patients which were inclusive of endometrial samples. 
Patients with isolated endometrial causes of abnormal uterine bleeding were included for this study and those with leiomyoma, cervical, vaginal pathology \& haemostatic disorders were excluded. All specimens were transported in $10 \%$ formalin to the pathology laboratory. the gross morphology were recorded. The tissue bits were processed in LIECA automatic tissue processor and paraffin blocks were prepared. Tissue sections were cut (4 -6 microns) \& stained with haematoxylin \& eosin stain. Microscopic examination was done by two pathologist so as to reduce inter observer bias. The data collected for this study was statistically analysed using chi-square test.

\section{RESULTS}

Isolated endometrial pathology as a cause of abnormal uterine bleeding was observed in $102(65.80 \%)$ of total cases. The remaining $53(29.71 \%)$ of cases who had leiomyoma, adenomyosis, cervical pathology with or without endometrial lesions were excluded from final analysis.

Table 1: Details of cases presenting with abnormal uterine bleeding from Feb. 2010 - Feb. 2012.

\begin{tabular}{|lll|}
\hline & $\begin{array}{l}\text { No. of } \\
\text { patients }\end{array}$ & $\%$ \\
\hline Total no. of cases & 155 & $100 \%$ \\
\hline $\begin{array}{l}\text { Isolated endometrial } \\
\text { pathology }\end{array}$ & 102 & $65.80 \%$ \\
\hline Leiomyoma & 46 & $29.67 \%$ \\
\hline Cervical pathology & 7 & $0.04 \%$ \\
\hline
\end{tabular}

The age of patients with abnormal uterine bleeding ranged from 20-70 yrs. in our clinical study. Abnormal
Uterine Bleeding was commonly seen amongst 40-50 yrs of age group and the predominant pattern noted was of normal cyclical endometrium, closely followed by disordered (cystic, glandular or cystic-glandular) proliferative endometrium, except in the age group of 60-70 yrs age group, a significant statistical association was seen between cases of abnormal uterine bleeding and the age group.

The specimen obtained for histopathological examination of the endometrial samples 102 samples comprised from dilatation \& curettage and rest 53 samples were obtained from hysterectomy specimen.

Histopathological examination showed various patterns in abnormal uterine bleeding as illustrated.

Histopathological examination showed various patterns in Abnormal Uterine Bleeding, consisting of normal cyclical pattern $(32.35 \%)$ of cases, this group of cases were offered on pharmacological or surgical treatment, they were given reassurance $\&$ were advised to follow up if they noticed any further irregularities in their menstrual cycle.

The cases with disordered proliferative endometrium- 34 (33.33\%), 31 cases belonged to reproductive age group and were offered pharmacological management and were kept under close surveillance.

Benign endometrial polyp was observed in 11 (10.78\%) of cases, pregnancy associated conditions complicated - 9 $(0.08 \%)$ of cases, endometrial hyperplasia without atypia was seen in $6(0.05 \%)$ of cases.

Table 2: Distribution of cases of abnormal uterine bleeding with isolated endometrial lesions according to the age group.

\begin{tabular}{|c|c|c|c|c|c|c|}
\hline \multirow{2}{*}{ Histopathology } & \multicolumn{5}{|c|}{ Age groups (yrs.) } & \multirow{2}{*}{ Total $(n=102)$} \\
\hline & $<20$ & 20-30 & $30-40$ & $40-50$ & $60-70$ & \\
\hline Normal cyclical pattern & - & 2 & 15 & 12 & 4 & $33(32.35 \%)$ \\
\hline $\begin{array}{l}\text { Disordered proliferative } \\
\text { endometrium }\end{array}$ & - & 1 & 20 & 10 & 3 & $34(33.33 \%)$ \\
\hline Benign endometrial polyp & - & 1 & 3 & 5 & 2 & $11(10.78 \%)$ \\
\hline $\begin{array}{l}\text { Endometrial hyperplasia } \\
\text { without atypia }\end{array}$ & - & - & - & 5 & 1 & $6(0.05 \%)$ \\
\hline Chronic endometritis & - & - & 2 & 1 & 1 & $4(0.03 \%)$ \\
\hline $\begin{array}{l}\text { Endometrial hyperplasia with } \\
\text { atypia }\end{array}$ & - & - & - & 1 & 4 & $5(0.04 \%)$ \\
\hline $\begin{array}{l}\text { Pregnancy associated } \\
\text { conditions }\end{array}$ & 1 & 4 & 4 & - & - & $9(0.08 \%)$ \\
\hline
\end{tabular}




\section{distribution of cases}

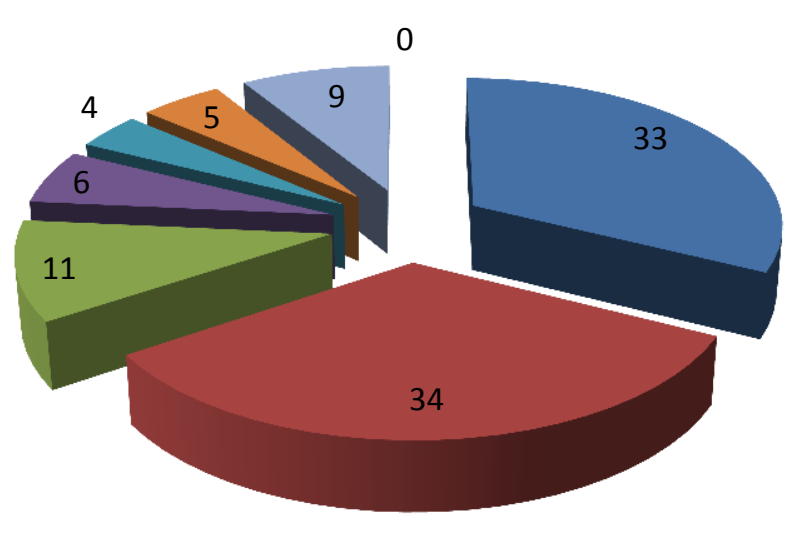

normal cyclical pattern

disordered proliferative
endometrium
benign endometrial polyp
endometrial hyperplasia
without atypia
chronic endometritis
endometrial hyperplasia with
atypia
pregnancy associated
conditions

Figure 1: Distribution of cases.

\section{DISCUSSION}

The causes of abnormal uterine bleeding include a wide spectrum of diseases of reproductive system and nongynaecologic causes as well. ${ }^{1}$ Organic causes can be further divided in to many subdivisions when an organic cause of abnormal uterine bleeding cannot be found, then by exclusion, a diagnosis is dysfunctional uterine bleeding is assumed. ${ }^{3}$

In about $20-30 \%$ of cases, the abnormal uterine bleeding is the result of a well-defined organic abnormality. ${ }^{4}$

In our case study, routine non invasive investigations for abnormal uterine bleeding was carried out which included - complete blood count, platelet count, liver function test, so as to rule out any coagulation or bleeding disorder. In women of reproductive age group, urine human chorionic gonadotropin (HCG) levels were evaluated to exclude pregnancy. To rule out endocrinological causes of which most common being thyroid function test was carried out.

Once, the above tests were found within normal limits, ultrasonography was carried out, on no demonstrable etiology dilatation \& curettage was considered diagnostic as well as therapeutic procedure.

The sensitivity of dilatation \& curettage for detection of endometrial abnormalities was reported to be as high as $96 \% .^{2}$

In our study, $32.65 \%$ of cases had normal cyclical pattern, these patients belonged to reproductive age group, they required no treatment and reassurance was offered to them.

The cases who required further evaluation and treatment belonged to reproductive age group with disordered proliferative endometrium -it denotes endometrial appearance that is hyperplastic but without an increase in endometrial volume. ${ }^{5}$ It also refers to a proliferative phase endometrium that does not seem appropriate for any one time in the menstrual cycle, this process is diffuse then focal. ${ }^{5}$

Amongst these 56 cases (disorderd proliferative endometrium + endometrial hyperplasia with \& with atypia + benign endometrial polyp), since, the underlying cause of all the conditions was unopposed estrogen, they were subjected to treatment with progesterone.

The above patients were advised tab. medroxyprogesterone acetate $5 \mathrm{mg}$ once daily from $5^{\text {th }}$ to $25^{\text {th }}$ day of menstrual cycle for a period of 3 months and their menstrual cycle were kept under close surveillance $\&$ were advised to follow up if any disturbance in menstrual cycle was noted.

Amongst, the above citied 56 patients, 5 cases underwent hysterectomy at other institution in respect to dissatisfaction owing to pharmacological treatment.

Thence, 51 patients were under study, out of which 11 cases followed up in their first - second cycle with similar complains and required repeat therapeutic dilatation \& curettage, on repeat dilatation \& curettage 5 
cases showed persistent endometrial hyperplasia with atypia and were warranted hysterectomy.

Rest 6 patients, were non compliant with the schedule and thence disturbance in menstrual cycle was noticed, they were given combined estrogen + progesterone preparations for better compliance \& were followed up after next 6 months, they were relieved of their complaints.

Amongst, the rest 40 cases they were compliant and were relieved of complaints, a close follow up on their menstrual calendar for 6 months was carried out, it revealed no further abnormalities.

\section{CONCLUSION}

Endometrial cause of abnormal uterine bleeding is age related pathology. Histopathological examination of endometrium is gold standard diagnostic tool in evaluation of abnormal uterine bleeding and a specific diagnosis helps us to plan \& individualise therapy for successful, resourceful management of abnormal uterine bleeding, where hysterectomy is not the answer, it is the interplay of hormones at work.
Funding: No funding sources

Competing interests: None declared

Ethical approval: The study was approved by the Institutional Ethics Committee

\section{REFERENCES}

1. Brenner PF. Differential diagnosis of AUB. Am J Obstet Gynecol 1996;175:766-9.

2. Albers JR, Hull SK, Wesley RM. Abnormal Uterine Bleeding. Am Fam Physician 2004;69:1915-26.

3. Litta P, Merlin F, Saccardi C, et al. Role of hysteroscopy with endometrial biopsy to rule out endometrial cancer in postmenopausal women with abnormal uterine bleeding. Maturitas 2005;50:11723.

4. Dahlenbach-Hellweg G. Histopathology of endometrium. $4^{\text {th }}$ edition New York: SpringerVeerlag; 1993.

5. Shankar M, Lee CA, Sabin CA, Economides DL, Kadir RA. von Willebrand disease in women with menorrhagia: a systematic review. BJOG 2004;111:734-40.

DOI: $10.5455 / 2320-1770$. ijrcog20130614

Cite this article as: Parmar J, Desai D. Study of endometrial pathology in abnormal uterine bleeding. Int J Reprod Contracept Obstet Gynecol 2013;2:182-5. 